\title{
NEWSLETTER
}

Kristen I. Barton, $P h D^{1,2}$,

Xiya $M a, B S c^{2,3}$

Adam Pietrobon, BSC ${ }^{4}$

Lauren C. Capozzi, $M D, P h D^{1}$

Karan Joshua Abraham, MSc $^{2,5}$

${ }^{1}$ Cumming School of Medicine, University of Calgary, Calgary, $\mathrm{AB}$

\section{Newsletter Fall 2018: \\ Clinician Investigator Trainee Association of Canada (CITAC)}

\begin{abstract}
Message from the President: Optimism for the Future
The Clinician-Investigator Trainee Association of Canada (CITAC) was established in 2006 to address issues relevant to Canadian trainees seeking dual training in medicine and research. As clinician-investigator (CI) trainees, we comprise but a fraction (less than 5\%) of all medical trainees. Our 'bilingual' careers render our individual paths less straightforward and more challenging. As a community, we have had to confront several disappointments, perhaps most notably the cessation of funding support for $\mathrm{MD} / \mathrm{PhD}$ programs in 2015, previously offered by the Canadian Institutes of Health Research (CIHR). Despite these individual and collective challenges, I remain optimistic and incredibly excited about our future. In my own work, I am reminded constantly that being trusted with the dual responsibility of patient care and innovation in medicine is a privilege to be cherished, rather than a burden to be feared. That which makes our path doubly challenging also makes it doubly rewarding. The progress that CITAC has made over the years only adds to my optimism, and I wish to take this opportunity to remind you of how far we have come and how much further we hope to go.
\end{abstract}

Correspondence to:

Clinician Investigator Trainee Association of Canada (CITAC)

E-mail:admin@citac-accfc.org 


\section{Message from the President: Optimism for the Future}

The Clinician-Investigator Trainee Association of Canada (CITAC) was established in 2006 to address issues relevant to Canadian trainees seeking dual training in medicine and research. As clinician-investigator (CI) trainees, we comprise but a fraction (less than 5\%) of all medical trainees. Our 'bilingual' careers render our individual paths less straightforward and more challenging. As a community, we have had to confront several disappointments, perhaps most notably the cessation of funding support for $\mathrm{MD} / \mathrm{PhD}$ programs in 2015, previously offered by the Canadian Institutes of Health Research (CIHR). Despite these individual and collective challenges, I remain optimistic and incredibly excited about our future. In my own work, I am reminded constantly that being trusted with the dual responsibility of patient care and innovation in medicine is a privilege to be cherished, rather than a burden to be feared. That which makes our path doubly challenging also makes it doubly rewarding. The progress that CITAC has made over the years only adds to my optimism, and I wish to take this opportunity to remind you of how far we have come and how much further we hope to go.

As an organization, we have grown from an initial cohort size of forty members in 2006 to our current membership size of several hundred in 2018. During this period, new partnerships with several organizations have blossomed. For instance, we now collaborate extensively with the Canadian Society for Clinical Investigation (CSCI), American Physician Scientists Association (APSA) and the Canadian Federation of Medical Students on projects that help advance both individual and shared goals. Through consistent and creative work, we have laid the infrastructure for research projects studying Canadian MD-PhD program structure and outcome. These initiatives have generated several key publications and findings, including the first-ever data showing that Canadian $\mathrm{MD} / \mathrm{PhD}$ program are highly successful at producing clinician-investigators. Such work informs educational policy and adds leverage to our advocacy efforts to reinstate funding support for CI training programs. Many of you will have attended our annual general meeting (AGM), which serves the educational and career needs of our members by offering workshops, mentorship opportunities and scientific review. A sponsorship agreement with MD Financial Management and continued support from the Burroughs Wellcome Fund has allowed us to accommodate a larger number of trainees at the AGM. Indeed, the AGM has experienced significant growth in recent years with over 170 trainees in attendance last year. Overall, by virtue of the efforts of prior CITAC leadership teams and your active participation as members, we have built significant momentum and a robust foundation to expand our activities even further.

This year, we have focused on strengthening these foundations while also expanding our scope of activities through a few key focused initiatives. First, we are launching our first nationwide CI trainee survey to gather information on demographic profile, financial situation, mentorship needs and gender-related issues relevant to our membership. We are developing this survey in consultation with our CSCI faculty advisors, and hope to distribute it through our internal contacts at various institutions. A separate CITAC working group will be responsible for data collection and all knowledge translation aspects, including peer-reviewed publications and sharing findings with program directors and our members, who are ultimately the intended beneficiaries of this research.

In collaboration with senior members of the editorial board of the Journal of Clinical Investigative Medicine (CIM), we have also created new opportunities for you to both share your research and reflect on your education and career path thus far, via published articles. On a separate front, we are aiming to bolster our advocacy efforts and enhance membership engagement and networking prospects, as well as to better showcase your achievements via targeted and strategic use of social media platforms. From a personal standpoint, it has been deeply rewarding to have the opportunity to lead these efforts and I want to take this opportunity to thank those of you who have helped get these initiatives off the ground, and also encourage more of you to participate in these endeavors when feasible. I wish to conclude by reiterating that we fully committed to enhancing the educational experience and career prospects of our incredibly talented and accomplished community of future physician-scientists in Canada. We thank you for your continued participation and look forward to seeing you all at our next AGM!

\section{Karan Joshua Abraham}

\section{CITAC's achievements in 2018}

\section{Surveying your MD/PhD program}

Literature surrounding the composition and success of Canadian $\mathrm{MD} / \mathrm{PhD}$ programs is still lacking and continued investigation is required. Earlier this year, a comprehensive survey was sent out to the $\mathrm{MD} / \mathrm{PhD}$ students at the University of Ottawa to collect objective and subjective metrics of the program's performance. The survey covered a variety of topics including award success and productivity, satisfaction with administrative support, career planning advice, program 
transition guidance and mentorship. While response data are still under analysis, preliminary results are being utilized by our Faculty to guide program changes, which will optimize student success and experience.

Hopefully, our survey results will highlight common positive elements and challenges faced by Canadian $\mathrm{MD} / \mathrm{PhD}$ programs. However, each $\mathrm{MD} / \mathrm{PhD}$ program operates within a unique structure that merits its own assessment. If you are interested in (or currently) examining your program's successes and challenges, feel free to contact Adam Pietrobon for details on our survey and evaluation process. We would be very happy to share some of our experiences to facilitate efforts at your own institution.

\section{Scientist-Clinician Executive Leadership Coaching Program}

The Leaders in Medicine (LiM) program represents a highly-motivated group of medical trainees who have dually embarked upon medical and graduate training at the University of Calgary. Many excellent leadership training programs are available at the University of Calgary, but none that are specifically tailored to the unique needs and challenges faced by LiM students. As the future leaders in medical care and research, it is imperative that LiM students learn effective ways to lead in a variety of settings based on their individual strengths. Recent research suggests one-on-one leadership coaching improves constructive leadership behaviours, including improved delegation and fostering resilience and goal attainment among leaders. The goal for the LiM Executive Leadership Coaching Program was to specifically address the unique challenges and opportunities LiM students face and offer tailored coaching to meet the needs of each student.

In collaboration with a professional Executive Coach who specializes in working with young professionals, we piloted a LiM Leadership Coaching Program that included a personal leadership style assessment (Core Values Inventory (CVI)), a small group workshop to discuss results from this assessment and a total of six one-on-one tailored leadership coaching sessions.

Overall, participants agreed that the CVI assessment was useful at identifying personal leadership qualities, that the group sessions were useful to interpret and integrate the information from the CVI and those who participated in the one-on-one sessions found them beneficial for improving leadership skills. Additional participant feedback was collected to help with further program improvement.

Overall, the LiM Executive Leadership Pilot Program was successful, reinforced the benefits of the program and provided an impetus to open it to additional LiM students. We plan to offer more LiM students the opportunity to assess their leadership style by completing the CVI assessment, attending a follow-up workshop and participating in one-on-one coaching to discuss qualities that can help them to be more effective leaders in medicine. 